\title{
RESILIENCE AND WORKABILITY AMONG BREAST CANCER SURVIVORS
}

\author{
Rocío Gómez-Molinero \\ Emotional Intelligence Laboratory \\ University of Cádiz (Cádiz, Spain) \\ rociogomezmolinero@gmail.com \\ Paula Ruiz-González \\ Instituto de Investigación e Innovación \\ Biomédica de Cádiz (INIBICA, Cádiz, Spain) \\ Antonio Zayas \\ Emotional Intelligence Laboratory \\ University of Cádiz (Cádiz, Spain) \\ Research Institute for Sustainable Social \\ Development (INDESS, Jerez de la Frontera, Cádiz, Spain) \\ Rocío Guil \\ Emotional Intelligence Laboratory \\ University of Cádiz (Cádiz, Spain) \\ Research Institute for Sustainable Social \\ Development (INDESS, Jerez de la Frontera, Cádiz, Spain)
}

Fecha de Recepción: 9 Abril 2019

Fecha de Admisión: 30 Abril 2019

\section{ABSTRACT}

Breast cancer is the most common neoplasia in women worldwide. Medical advances in prognosis and treatments have improved survival rates, however, many women report physical and psychological problems derived from the impact and the administered treatments that can undermine breast cancer survivors' workability. Given that breast cancer occurs at working age (35-65 years) and due to the importance that work has in their recovery process, it is crucial to determine the psychological resources that breast cancer survivors may use to reestablish their ability to work. In this sense, resilience understood as the ability to successfully adapt in the face of stress and adversity may play an important role.

Hence, the aim of this study is to explore resilience levels in breast cancer survivors and to study its relationship with workability. The sample was comprised of 44 breast cancer survivors of Spain, with a mean age of 51.93 (SD = 8.77). Participants completed the Wagnild and Young Resilience Scale (Spanish version adapted by Novella, 2002) and Work Ability Index (WAI, Tuomi et al., 1997).

The results of the descriptive statistics revealed that breast cancer survivors displayed high lev- 
els of resilience. Moreover, the results of the Pearson correlation indicated that there was a significant positive association between global resilience and workability $(r$

$=.33, p=.03)$, as well as between the dimensions self-confidence $(r=.37, p=.01)$ and personal satisfaction $(r=.33, p=.03)$. Age did not correlate with resilience nor with workability.

Thus, identifying the factors that positively influence breast cancer survivors' adjustment to working life can help to develop interventions with the aim to restore working ability in this population. Besides, given the importance that return-to-work have in this population, this research may contribute to expanding knowledge regarding the recovery process in breast cancer survivors.

Keywords: resilience; work ability; breast cancer survivorship; return to work

\section{INTRODUCTION}

Cancer refers to a set of diseases in which one or more cells of the organism are altered in such a way that they proliferate in an uncontrolled manner, giving rise to millions of cells with the same alteration, some of which can be extended to other cells, parts of the body, and even invade them. It is one of the most significant diseases of our time due to its high incidence and its consequences, representing the second cause of mortality in the world. This makes this illness one of the most relevant health problems (World Health Organization, WHO, 2002). Currently, and according to the WHO, cancer is one of the four chronic diseases with higher prevalence along with cardiovascular diseases, chronic respiratory diseases, and diabetes (Alwan, 2011). It is estimated that its incidence, worldwide, will rise from 10 to 15 million cases by the year 2020 and the number of deaths will rise from 6 to 10 million (WHO, 2017).

In Spain, as in the rest of the countries of their socioeconomic environment, malignant tumors represent the second cause of death, after cardiovascular diseases. According to the Spanish Society of Medical Oncology (SEOM, 2017), in 2015 the mortality rate for malignant tumors was 231 per 100,000 inhabitants, which accounted for $25 \%$ of all deaths that occurred in that year. In men, the mortality rate due to malignant tumors was 287 per 100,000 inhabitants, which accounted for $31 \%$ of all deaths, while in women it was 177 per 100,000 inhabitants, representing $20 \%$ of them. Although the relative importance of cancer mortality has increased in developed countries, this is not due to an increase in cancer mortality since it is in a slight decline, but to a decrease in mortality due to cardiovascular diseases.

The most frequent neoplasia in women is breast cancer, representing $16 \%$ of all cancers suffered by women (International Agency for Research on Cancer, 2002, SEOM, 2017, American Cancer Society, 2011). Breast cancer incidence is increasing due to life expectancy improvement and advanced diagnostic techniques (Carmona-Torres et al., 2018). However, mortality follows a descending pattern that can be attributed to the significant medical advances achieved in this century (Ferro et al., 2014). Still, the physical, emotional, and social problems experienced by a significant proportion of breast cancer survivors can become chronic, i.e. fatigue, pain, cognitive deficit, depression, etc. (Smith et al., 2018).

The growing population of survivors shows long-term needs related to the multidimensional aspects of the quality of life (physical, psychological, social, independence, environment, and spirituality), that remain unattended by health policies. In addition, the diagnosis impact and the administered treatments can lead to continuous physical, emotional, and psychological distress, negatively affecting their ability to work. Workability is a multidimensional concept with many definitions and conceptualizations. This construct is generally attributed to Professor Juhani IImarinen, who defines it as the "potential of a person, man or woman, to perform a certain task in a given time. The development of individual functional capacity must be in accordance with the demands of work" (IImarinen and Tuomi 1993). 
Given that the Spanish legislative framework is inflexible and does not contemplate the progressive incorporation in the workplace, $47 \%$ of women with breast cancer will end up in permanent disability and $53 \%$ will return to work after one year since diagnosis (López-Guillén García). These surviving workers have suffered a long process sick absence, showing an important deterioration in their quality of life and personal suffering. In fact, as de Boer et al. (2009) stated in their meta-analysis, breast cancer survivors have a 1.3 times higher risk of becoming unemployed compared to the general population. In this sense, breast cancer survivors have lower participation in the labor market (Chaker et al., 2015). Moreover, the low rate of return to work represents an important economic burden for society, since around $70 \%$ of new cases of breast cancer occur in women of working age (Global Burden of Disease Study, 2015). Hence from the point of view of society, is an economic and social imperative to encourage patients to return to work whenever possible.

Literature concerning work ability has revealed that breast cancer survivors show lower levels of work capacity than groups of women without cancer (Hansen, Feuerstein, Calvio and Olsen, 2008; Lindbohm et al., 2012). More recently, Ho et al. (2018) explored the determinants of workability in 321 breast cancer survivors (with a previous diagnosis of one year) and its relation with the physical, psychological, and social aspects reported by the patient. The results showed that of work was not associated with time since diagnosis, ethnicity or clinical characteristics, and that $37 \%$ of survivors had a reduced workability. In addition, higher levels of depression, financial difficulty, physical fatigue, and a worse state of global health were negatively associated with the ability to work.

Due to its high incidence (1 in 10), the increasing participation of females in the labor force in recent decades, and given that the majority of the women affected by this disease are at working age (the average age of diagnosis is between 18-65 years), it is extremely important to examine the conditions under which women diagnosed with breast cancer preserve their ability to work.

According to Rutter (1990), a resource, internal and external, acts as a protective factor if it moderates risk. In this sense, the literature has highlighted the role of resilience as a protective factor. Defining resilience has been a challenge for academics since this term has been used in a wide variety of contexts. In general terms, resilience can be defined as the process of adapting well in the face of adversity (American Psychological Association, 2017).

Campbell-Sills and colleagues (2006) found that individuals who are highly resilient engage more often in adaptive coping skills and convert stressful situations into opportunities for learning and development. Therefore, resilience, construct framed in the positive psychology field, can be understood as a protective factor since it prevents from maladaptive strategies.

Several studies have highlighted the prevalence of high levels of resilience in breast cancer survivors (i.e. Dooley, Slavich, Moreno, and Bower, 2011; Donovan and Oppenheimer, 2014; Zhang, Zhao, Cao, and Ren, 2017). Likewise, experimental evidence in the field of psychology has revealed that when women find meaning in the traumatic experience, their psychological adjustment is much more adequate (Bellizzi and Blank, 2006; Scrignaro, Barni, and Magrin, 2010) showing fewer emotional scars after treatments (Aydin, 2008; Salsman, Segerstrom, Brechting, Carlson, and Andykowski, 2009) which leads to a healthier lifestyle, with a greater commitment to their well-being (Vázquez and Castilla, 2007). Specifically, a recent study developed by Zayas et al. (2018) evaluated resilience levels in breast cancer women and their relationship with life satisfaction, showing that women with cancer displayed higher levels of resilience. However, regression analysis found no significant association between these levels and satisfaction with life.

The relation between resilience and the workplace have focused on the benefits of this variable in professionals who have to deal with death (Paton, 2005, Linley and Joseph, 2006) or in war veterans (Tedeschi and McNally, 2011). However, the relationship of resilience with workability, as well 
as with other labor indicators, is unknown and it is necessary to deepen in the study of its impact in the organizational context. Therefore, the purpose of the present study is to explore resilience and workability levels in breast cancer survivors and to study their relationship with workability.

\section{METHODS}

\section{Participants and procedure}

The sample was composed of 44 breast cancer survivors from Cádiz (Spain) and average age was 51.93 (SD = 8.77). Participants were given a questionnaire with all the scales presented at the same time. Breast cancer survivors had no time limitation to complete the scales and the responsible of the investigation was presented at the time they fulfill the questionnaires. Participation was anonymous and voluntary. Before completing the questionnaire, participants had to sign an informed consent.

\section{Instruments}

Workability, Work Ability Index (WAl; Tuomi et al., 1997) developed by the Finnish Institute of Occupational Health, is a questionnaire that evaluates the perceived workability. It was originally developed in a follow-up study of elderly employees. Although the Index was developed for the first time to be used as a research method, it is widely applied as a practical tool to measure subjective workability. The Index is determined on the basis of the answers to a series of questions that take into consideration job demands, health status, and worker personal resources. It contains seven subscales (range 7-49) and includes dimensions for the capacity of physical and mental work and a single question about the ability to work in general. The seven elements are:

Current workability in comparison with the best work capacity in two years.

Workability in relation to work demands (self-evaluation).

The number of currently diagnosed diseases and estimated work disability of these illnesses.

Absenteeism due to illness in the last 12 months.

Mental resources.

For the purpose of this research, only total workability will be considered.

Resilience, Wagnild y Young Resilience Scale (1993), Spanish version adapted by Novella (2002). This instrument assesses the ability of students to face adverse situations. The scale is composed of 25 items, in a 7-point Likert scale, ranging from 1 (totally disagree) to 7 (totally agree). All items are positively scored. The possible total scores range from 25 to 175 with higher scores reflecting higher resilience. The interpretation of total resilience is performed by adding the scores of each item, obtaining: Non-resilience (25-74 points); Low resilience (75-100 points); Average resilience (101-125 points); High resilience (126-150 points) and very high resilience (151-175 points). It includes, besides a global resilience measure, five dimensions: existential aloneness (range 3-21), feeling of freedom and sense of uniqueness; self- reliance (range 7-49), ability to believe in oneself and one's abilities; equanimity (range 4-28), referrers to the ability of the person to show a balanced perspective concerning their own life and experiences, take things slowly, and moderating their attitudes to an adverse event; perseverance (range 7-49), persistence in the face of adversity or a threatening situation, together with a strong desire for achievement and self-discipline; and purposeful life (range 4-28), people's ability to understand the meaning of life and their contributions.

\section{RESULTS}

Descriptive statistics and Cronbach's alphas were calculated for each measure of the sample 
(Table 1). As we can see in Table 1, and based on the scale interpretation values, breast cancer survivors showed high levels of total resilience and low levels of work ability. Besides, participants also displayed high levels in all dimensions of resilience (equanimity, perseverance, self-reliance, purposeful life, and existential aloneness).

Table 1. Descriptive Statistics

\begin{tabular}{lcccccc}
\hline & $N$ & Min & Max & Mean & $S D$ & $\alpha$ \\
\hline Age & 44 & 29 & 67 & 51,93 & 8,77 & - \\
Equanimity & 44 & 11,00 & 27,00 & 19,57 & 3,76 &, 59 \\
Perseverance & 44 & 31,00 & 47,00 & 41,27 & 4,22 &, 82 \\
Self-reliance & 44 & 27,00 & 49,00 & 41,23 & 5,63 &, 87 \\
Purposeful life & 44 & 14,00 & 28,00 & 23,16 & 3,25 &, 68 \\
Existential aloneness & 44 & 13,00 & 21,00 & 17,95 & 2,26 &, 58 \\
Total Resilience & 44 & 111,00 & 169,00 & 143,18 & 13,85 &, 89 \\
Workability & 44 & 10,00 & 48,00 & 27,44 & 11,33 &, 80 \\
\hline
\end{tabular}

Note. $S D=$ standard deviation; $\alpha=$ Cronbach $\alpha$

values

In order to determine if total resilience including all its subscales and age were related to work ability, Pearson's bivariate correlations were conducted. As we can see in Table 2, age did not significantly correlate with any variable assessed. However, workability was positively and statistically significant associated with perseverance, self-reliance and global resilience. Suggested levels of dispositional optimism are higher as age increases for this sample. Moreover, undergraduates with higher levels of optimism also displayed high levels of resilience

Table 2. Pearson's Bivariate Correlations

\begin{tabular}{lcccccccc}
\hline & 1 & 2 & 3 & 4 & 5 & 6 & 7 & 8 \\
\hline 1. Age & 1 & & & & & & & \\
2. Equanimity &, 23 & 1 & & & & & & \\
3. Perseverance &, 04 &, 10 & 1 & & & & & \\
4. Self-reliance &, 19 &, 20 &, $52^{* *}$ & 1 & & & & \\
5. Purposeful life &, 14 &, 04 &, $57^{* *}$ &, $65^{* *}$ & 1 & & & \\
6. Existential aloneness &, 23 &, 12 &, $49^{* *}$ &, $65^{* *}$ &, $57^{* *}$ & 1 & & \\
7. Total Resilience &, 22 &, $41^{* *}$ &, $76^{* *}$ &, $88^{* *}$ &, $77^{* *}$ &, $74^{* *}$ & 1 & \\
8. Workability &, 04 &, 17 &, 14 &, $33^{*}$ &, $37^{*}$ &, 11 &, $33^{*}$ & 1 \\
\hline
\end{tabular}

Note. $* * \mathrm{p}<0,01 * \mathrm{p}<0,05$ (bilateral)

\section{DISCUSSION AND CONCLUSIONS}

This research aimed to determine the levels of workability and resilience and the relationship between these two variables among a sample of breast cancer survivors of Cádiz (Spain). Literature 
up to date has been focused on resilience and workability levels in this population, however, little is known about the relationship between these two variables and the protective role of resilience maintaining the ability to work.

The results of the study indicated that sample women displayed high levels of total resilience as well as high levels in all its subscales (equanimity, perseverance, self- reliance, purposeful life, and existential aloneness). That means that breast cancer survivors face their illness in an adaptive way, showing great levels of feelings of freedom and sense of uniqueness, higher ability to believe in themselves and in her abilities, showing a balanced perspective concerning their own life and experiences, a higher persistence in the face of adversity or a threatening situation, and great ability understanding the meaning of life and their contributions.

Our results are in line with existent literature supporting our view that breast cancer survivors find meaning in the traumatic experience and show a much more adequate psychological adjustment (Scrignaro, Barni, and Magrin, 2010). Besides, this high levels of resilience can contribute to diminish their emotional scars after the administered treatments (Bozo et al., 2009; Salsman, Segerstrom, Brechting, Carlson, and Andykowski, 2009) and may help them to achieve greater levels of wellbeing (Vázquez and Castilla, 2007).

Regarding workability, participants displayed low levels of work capacity, showing low potential to perform a certain task in a given time. Again, our results are in line with previous research that revealed differences between breast-cancer and healthy women in their workability levels (Hansen, Feuerstein, Calvio and Olsen, 2008, Lindbohm et al., 2012). Moreover, and as the literature suggests, this low levels of workability may be due to higher levels of depression, financial difficulty, physical fatigue, and a worse state of global health were negatively associated with the ability to work (Ho et al., 2018).

Results of this research appear to confirm that resilience may act as a protective factor in the face of workability. As the correlation analysis showed, global resilience, as well as self-reliance and purposeful life dimensions, were positively associated with workability. These results suggested that women how find meaning from the stressful situation experienced will display better adjustment to the workplace resulting in higher levels of their ability to deal with work demands.

Finally, although during the last decade there has been an increase of research concerning the effect of cancer in various aspects of employment and the working life, it is necessary to deepen in the study of how the diagnosis and the administered treatments of this pathological process undermine workability and which factors contribute to maintain or restore their work capacity.

Future research should investigate the effectiveness of interventions aimed to enhance survivors' resilience in order to facilitate a successful return to work in breast cancer women. In this sense, patients able to deal with stressors could achieve better performance levels and might decrease anxiety and depression levels derived from unsatisfactory return to work.

\section{REFERENCES}

Alex Linley, P., Joseph, S., Harrington, S., \& Wood, A. M. (2006). Positive psychology: Past, present, and (possible) future. The Journal of Positive Psychology, 1(1), 3-16.

Alwan, A. (2011). Global status report on noncommunicable diseases 2010.

World Health Organization.

American Psychological Association (2017). The Road to Resilience. Available online at: http://www.apa.org/helpcenter/road-resilience.aspx

Bellizzi, K. M., \& Blank, T. 0. (2006). Predicting posttraumatic growth in breast cancer survivors. Health Psychology, 25(1), 47. 
Campbell, A., Converse, P.E. y Rodgers, W.L. (1976). The quality of American life: perceptions, evaluations and satisfactions. Russel Sage Foundation, New York: Wiley.

Carmona-Torres, J. M., Cobo-Cuenca, A. I., Martín-Espinosa, N. M., Piriz- Campos, R. M., LaredoAguilera, J. A., \& Rodríguez-Borrego, M. A. (2018). Prevalencia en la realización de mamografías en España: análisis por comunidades 2006-2014 y factores que influyen. Atención Primaria, 50(4), 228-237.

Chaker, L., Falla, A., van der Lee, S. J., Muka, T., Imo, D., Jaspers, L., ... \& Pazoki, R. (2015). The global impact of non-communicable diseases on macro- economic productivity: a systematic review. European Journal of Epidemiology, 30(5), 357-395.

De Boer, A. G. E. M., Verbeek, J. H. A. M., Spelten, E. R., Uitterhoeve, A. L. J., Ansink, A. C., De Reijke, T. M., ... \& Van Dijk, F. J. H. (2008). Work ability and return-to-work in cancer patients. British journal of cancer, 98(8), 1342.

Donovan, A., \& Oppenheimer, C. (2014). Science, policy and place in volcanic disasters: insights from Montserrat. Environmental Science \& Policy, 39, 150-161.

Dooley, L. N., Slavich, G. M., Moreno, P. I., \& Bower, J. E. (2017). Strength through adversity: Moderate lifetime stress exposure is associated with psychological resilience in breast cancer survivors. Stress and Health, 33(5), 549-557.

Ferro, A., Peleteiro, B., Malvezzi, M., Bosetti, C., Bertuccio, P., Levi, F., ... \& Lunet, N. (2014). Worldwide trends in gastric cancer mortality (1980-2011), with predictions to 2015, and incidence by subtype. European journal of cancer, 50(7), 1330-1344.

Hansen, J. A., Feuerstein, M., Calvio, L. C., \& Olsen, C. H. (2008). Breast cancer survivors at work. Journal of Occupational and Environmental Medicine, 50(7), 777-784.

Ho, P. J., Hartman, M., Gernaat, S. A., Cook, A. R., Lee, S. C., Hupkens, L., \& Verkooijen, H. M. (2018). Associations between workability and patient-reported physical, psychological and social outcomes in breast cancer survivors: a cross-sectional study. Supportive Care in Cancer, 26(8), 2815-2824.

IImarinen, J., \& Tuomi, K. (1993). Past, present and future of work ability. In

Proceedings of the 1st International Symposium on Work Ability, Helsinki.

Lindbohm, M. L., Taskila, T., Kuosma, E., Hietanen, P., Carlsen, K., Gudbergsson, S., \& Gunnarsdottir, H. (2012). Work ability of survivors of breast, prostate, and testicular cancer in Nordic countries: a NOCWO study. Journal of Cancer Survivorship, 6(1), 72-81.

López-Guillén García, A., Pardo, V., \& Manuel, J. (2017). Retorno al trabajo tras cáncer de mama. Medicina y Seguridad del Trabajo, 63(246), 51-67.

Novella, A. (2002). Incremento de la resiliencia luego de la aplicación de un programa de psicoterapia breve en madres adolescentes. Tesis para optar el grado de Magíster en Psicología, mención en Psicología clínica y de la salud.

Organización Mundial de la Salud (2002). Manual de instrucciones de la OMS sobre calidad de vida, 61-71: Ginebra. Retrieved from: http://apps.who.int/medicinedocs/pdf/s4930s/s4930s.pdf.

Rutter, M. (1990). Commentary: Some focus and process considerations regarding effects of parental depression on children. Developmental psychology, 26(1), 60.

Salsman, J.M., Segerstrom, S.C., Brechting, E.H., Carlson, C.R., \& Andrykowski, M.A. (2008). Posttraumatic growth and PTSD symptomatology among colorectal cancer survivors: A 3month longitudinal examination of cognitive processing. Psycho-Oncology, 18, 30-41.

Schmidt, M. E., Wiskemann, J., \& Steindorf, K. (2018). Quality of life, problems, and needs of disease-free breast cancer survivors 5 years after diagnosis. Quality of Life Research, 27(8), 20772086. 
Scrignaro, M., Barni, S., \& Magrin, M. E. (2011). The combined contribution of social support and coping strategies in predicting post traumatic growth: a longitudinal study on cancer patients. Psycho oncology, 20(8), 823-831.

Sociedad Española de Oncología Médica (2017). Las cifras del cáncer en España.

Tedeschi, R. G., \& McNally, R. J. (2011). Can we facilitate posttraumatic growth in combat veterans?. American Psychologist, 66(1), 19.

Tuomi, K., Ilmarinen, J., Martikainen, R., Aalto, L., \& Klockars, M. (1997). Aging, work, life-style and work ability among Finnish municipal workers in 1981- 1992. Scandinavian journal of work, environment \& health, 58-65.

Vázquez, C., \& Castilla, C. (2007). Emociones positivas y crecimiento postraumático en el cáncer de mama. Psicooncología, 4(2/3), 385.

Wagnild, G., y Young, H. (1993). Development and psychometric. Journal of nursing measurement, 1(2), 165-17847.

Zayas, A. \& Guil, R. (2018). El cáncer de mama desde un enfoque biopsicosocial de la salud. Perspectiva salutogénica. Sevilla: Fenix Editora.

Zhang, H., Zhao, Q., Cao, P., \& Ren, G. (2017). Resilience and quality of life: Exploring the mediator role of social support in patients with breast cancer. Medical science monitor: international medical journal of experimental and clinical research, 23, 5969. 